\begin{tabular}{|c|c|c|}
\hline 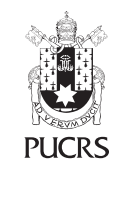 & $\begin{array}{l}\text { ESCOLA DE } \\
\text { HUMANIDADES }\end{array}$ & $\begin{array}{l}\text { Revista de Filosofia da PUCRS } \\
\text { Veritas, Porto Alegre, v. } 65 \text {, n. 1, p. 1-12, jan.-mar. } 2020 \\
\text { e-ISSN: 1984-6746 | ISSN-L: 0042-3955 }\end{array}$ \\
\hline dei) $\mathrm{htt}$ & $\mathrm{rg} / 10.15448 / 1984-6746.2020 .1 .36279$ & \\
\hline
\end{tabular}

SEÇÃO: TRADUÇÃO

\title{
Eric Weil e o futuro da filosofia
}

\author{
Eric Weil and the future of philosophy \\ Eric Weil y el futuro de la filosofía
}

Judikael Castelo Branco ${ }^{1}$ orcid.org/0000-0002-4551-2531 judikael.castelo@mail.uft.edu

Recebido em: 5 nov. 2019. Aprovado em: 27 dez. 2019. Publicado em: 12 mai. 2020.
Resumo: L'avenir de la philosophie é a conferência proferida por Eric Weil (19041977) à Association régionale des professeurs de philosophie, da cidade de Nice. em 1974. Nela, ficam destacadas alguns temas fundamentais com os quais o autor se preocupou a partir da publicação da sua Logique de la philosophie, em 1950. A tradução do texto vem aqui precedida por uma apresentação que visa a. justamente, sublinhar elementos essenciais à compreensão da obra weiliana, e presentes na conferência, tais como o caráter capital do problema da violência para a filosofia, a importância da escolha pela razoabilidade e, por fim, a filosofia compreendida na passagem da certeza à discussão.

Palavras-chave: Violência. Futuro. Filosofia. Sentido.

Abstract: L'avenir de la philosophie is the lecture given by Eric Weil (1904-1977) to the Association régionale des professeurs de philosophie, Nice, 1974. Weil highlights some fundamental themes with which the author is concerned since the publication of his Logique de la philosophie (1950). The translation of the text is preceded here by a presentation that aims precisely to underline elements essential to the understanding of Weilian work and present in the conference. such as the main character of the problem of violence for philosophy, the importance of choosing reasonableness and, finally, the philosophy understood in the passage from certainty to discussion.

Keywords: Violence. Future. Philosophy. Sense.

Resumen: L'avenir de la philosophie es la conferencia de Eric Weil (1904-1977) a la Association régionale des professeurs de philosophie, en la ciudad de Niza, en 1974. En nesta conferencia, Weil destaca algunos temas fundamentales con que él se ocupa desde la publicación de su Logique de la philosophie. La traducción del texto está precedida aquí por una presentación que subraya elementos esenciales para la comprensión del trabajo weiliano y presentes en la conferencia, como el papel del problema de la violencia para la filosofía, la importancia de elegir lo razonable y, finalmente, la filosofía entendida en el pasaje de la certeza a la discusión. Palavbas clave: Violencia. Futuro. Filosofia. Sentido.

\section{Apresentação}

"O futuro da filosofia" é o texto da conferência proferida por Eric Weil à Association régionale des professeurs de philosophie, da cidade de Nice, em dezembro de 1974. Para quem conhece a obra do autor, é evidente a retomada de alguns dos temas fundamentais com os quais ele se ocupou sobretudo a partir da publicação da Lógica da filosofia. sua obra máxima, em 1950. A nosso ver, uma apresentação adequada desse escrito exige tanto o esforço de situá-lo no conjunto da reflexão weiliana, quanto o destaque da sua relevância, quase 45 anos depois, 
para o público ao qual propomos a sua leitura: os lusófonos, sobretudo brasileiros, interessados em filosofia.

No tocante à relação de "O futuro da filosofia" com o resto da obra weiliana, há de se considerar o lugar do texto na história da produção do seu autor, bem como a sua ligação temática com os principais argumentos defendidos por Weil em outros escritos. Dessa forma, a abordagem se desdobra porquanto toma o texto primeiro a partir de brevíssimos acenos de cunho histórico-biográfico, e, em seguida, de modo mais demorado, em uma perspectiva própria, entre filosófica ou sistemática.

Weil ensina filosofia na Faculdade de Letras da Universidade de Lille de 1956 a 1968, quando se transfere para Nice, onde leciona até 1974. Esse translado para uma cidade mais ao Sul da França não é fortuito, e responde a interesses pessoais do filósofo, como, por exemplo, ficar mais perto da Itália, muito mais se explica pelo projeto de desenvolvimento intelectual da Universidade de Nice; projeto em vista do qual a universidade procurou nomes como Jean Alexandre Dieudonné, Pierre Guiraud, JeanWilliam Lapierre, Robert Ellrodt, além, é claro, de Eric Weil (CHIARA, 2015, p. 34). Portanto, "O futuro da filosofia" é apresentado ao seu público imediato por um filósofo que àquela altura conta certamente com o reconhecimento tanto do seu valor para os estudos hegelianos na França ${ }^{2}$ quanto da qualidade das suas publicações, e que naquele momento em especial está inserido num grande programa de desenvolvimento da formação acadêmica da região.

Devemos ainda observar o fato de que se trata de um texto da plena maturidade do autor. Com efeito, os anos de 1975 e 1976 assistiram a progressiva fragilização da saúde de Weil, dando ao "O futuro da filosofia" um status de quasetestamento filosófico do autor. Nele, finalmente, Weil não perde a oportunidade de repassar em resumo algumas das teses basilares da sua filosofia, numa espécie de prestação de contas do proprio pensamento, mas, como o título sublinha, num olhar que não é apenas retrospectivo senão plenamente prospectivo por estar enraizado por inteiro no presente - o que o autor sublinha já no fim do primeiro parágrafo.

No que concerne à relação com a arquitetônica da obra weiliana, queremos simplesmente destacar algumas noções essenciais da natureza e da tarefa da filosofia retomadas pelo autor em "O futuro da filosofia".

Antes de tudo, o texto destaca em várias passagens o lugar central que a violência deve ocupar na reflexão filosófica contemporânea. De fato, só pode haver algum futuro para a filosofia se esta levar em conta não apenas a possibilidade da rejeição do discurso coerente. mas a sua efetiva realização histórica. Dito de outro modo, a filosofia, e está aqui, sabidamente, o imo do pensamento de Weil, vê-se lançada numa "crise de confiança" aprofundada justamente pelo fenômeno contemporâneo do anúncio do "evangelho da pureza da violência".

Não há dúvidas sobre o papel da violência na construção dos argumentos de Weil, no entanto, parece-nos válido remontar a um testemunho seguro de como ela assume um lugar central; é o que faz Livio Sichirollo ao recuperar as palavras de Weil a Massimo Barale: "Acontece, em filosofia, que os mestres involuntários ensinem mais do que tantos mestres voluntariosos. Meu mestre involuntário foi Adolf Hitler" (SICHIROLLO, 1997. p. 32). Tratando-se desse mestre, só se pode aprender uma única lição. Weil então não pode não pensar o fato da violência, entendida no conjunto de sua obra sob registros diferentes e tão dificeis de apreender quanto nos é difícil a apreensão da própria razão (BERNARDO, 2011, p. 47). No entanto, naquilo que a história recente nos deu de novidade, essa violência se mostrou na sua pureza nas experiências totalitárias, de um lado, e, de outro, na insatisfação do indivíduo moderno, quer dizer, no "tédio do progresso infinito e insensato" (WEIL, 1969, p. 83), "produzido pela insatisfação de um interesse satisfeito", fruto da desnaturalização do tempo livre em esvaziamento dedicado à diversão viciosa, que

2 Sobre o papel de Weil na recepção de Hegel às margens do Sena, cf. CASTELO BRANCO; COSTESKI, 2019. 
faz da violência gratuita "o único passatempo verdadeiro" (WEIL, 2003a, p. 303). ${ }^{3}$

Trata-se, então, da consideração de uma nova figura da violência, manifestada, para a filosofia, como a recusa do filosofar tout court. Há, para Weil, a criação de um novo quadro no qual toda coerência é falsa coerência. Nessa moldura, a recusa da filosofia alcança uma escala vista só recentemente na história do pensamento, quer dizer, não se trata mais da recusa de uma determinada filosofia em nome de outra que pretensamente a supere, mas de uma refutação completa e com conhecimento de causa; é a própria filosofia, portanto, que é posta em questão, nas palavras de Weil: não se trata mais de um ataque visando "uma tal filosofia em nome da filosofia, lesse ataque] não se inspira pela vontade de filosofar".

Em segundo lugar, a filosofia, fruto de uma "escolha primordial" (WEIL, 2012, p. 90), pode ser entendida como uma como o esforço de quem se vê imediatamente diante de um mundo no qual a busca de sentido não se mostra como a primeira atitude realizada. Podemos avançar na questão deixando de lado uma ideia vaga de filosofia e tomá-la, com Weil, como "ciência do sentido" (WEIL, 2012, p. 593), "realização do sentido" (WEIL, 2003a, p. 34) e "esforço em direção do sentido" (WEIL, 1969, p. 85). Logo, ela se identifica constitutivamente com o filósofo, pois - é ao mesmo tempo banal e fundamental afirmar - "não existe filosofia sem filósofos", há filosofia porque há quem livremente escolheu compreender a textura da realidade, isto é, esforçar-se para "prender juntas as contradições na unidade de um sentido" (WEIL, 2012, p. 599, grifo do autor). ${ }^{4}$

A descoberta de que, com conhecimento de causa, "é sempre possivel recusar a questão do sentido" (WEIL, 1987, p. 19), recoloca no centro dos nossos quadros teóricos contemporâneos o sentido da questão, quer dizer, exige repensar as condições de possibilidade da escolha da filosofia. Não foi por acaso que as justificativas da filosofia ganharam um capítulo tão vigoroso na segunda metade do século passado; para pensar só no terreno da língua adotada por Weil, resgatamos os exemplos, bem distintos, de Jean-François Lyotard (2013) e Pierre Hadot (2016). Mas Weil não se limita a assumir a compreensão da filosofia como um esforço sempre in fieri, antes sustenta nesse domínio uma postura absolutamente particular: a filosofia é injustificável. ${ }^{5}$

Em terceiro lugar, ela se faz fundamentalmente como passagem da certeza à discussão. Dito de outro modo, exige a desinstalação de qualquer perspectiva ideológica na direção da compreensão do sentido. Essa passagem é essencialmente anti-ideológica justamente porque o esforço da compreensão problematiza também o ponto de vista de quem quer compreender, isto é, o filósofo deve pôr sempre em questão também os limites da própria perspectiva. Daqui decorrem duas consequências inevitáveis. Primeiramente o fato de que essa escolha não se concilia de nenhuma forma com generalizações abstratas ou com propostas pretensamente neutras ou indiferentes. Weil é incisivo e as inúmeras repetições disso

\footnotetext{
Em dois textos bem distintos, Weil traz praticamente numa mesma imagem como essa reação de recusa violenta do pensamento se impôs à sua reflexão. Primeiro, na Lógica da filosofia, ele assevera que "o pensamento deve estar bem avançado para que alguém possa declarar que saca seu revólver assim que ouve a palavra 'civilização'" (WEIL, 2012, p. 92). Com efeito, esse quadro é retomado em La culture, escrito publicado apenas em 2003: "um chefe da SS declarou um dia numa reunião pública: 'Quando eu ouço a palavra cultura, saco o meu revólver'". Diante dessa atitude o filósofo não pode absolutamente restar indiferente, o autor continua: "pode-se supor que ele não falasse de cultura com conhecimento de causa, mas o seu caso é o mais instrutivo. Por que esse homem detestaria a esse ponto a cultura e o homem culto? Se a questão the fosse colocada, é provável que respondesse com um simples 'porque' muito ameaçador. Mas, colocando-nos em seu lugar, por impossivel que seja, responderiamos: porque o homem culto é politeista e, portanto, ateu, um homem que venera todos os deuses apenas para não temer a nenhum". Só então podemos passar a um esboço do homem de cultura: "Com efeito, o homem culto se distingue de todos os outros homens por um traço, um único traço, mas que é suficiente para fazer dele um monstro e um objeto de desgosto para todos os outros: ele reprova a violência. Ele não acredita, não quer acreditar, que haja coisas, opiniões ou decisões pelas quais valha a pena matar ou morrer" (WEIL, 2003b, p. 8).

4 Na conferência "Filosofia e realidade", o autor afirma justamente que "a filosofia não existe no mesmo sentido em que existe uma física e uma matemática: só existe o filosofar e é somente para a vontade de filosofar que os conteúdos, se tal termo tem seu lugar aqui, dos pensamentos do passado revelam seu sentido e a intenção que os inspirou. Só o sopro do interesse livre restitui a vida às ossadas depositadas nas sepulturas das doxografias" (WEIL, 2019, p. 211-212, grifo do autor).

5 Para nosso autor, com efeito, é "impossivel provar a necessidade da escolha pela [da filosofia] em detrimento daquela da [violência]: isto seria uma contradição de termos, pois nenhuma prova é possivel onde ainda não se reconheceu o principio da demonstração, quer dizer, a coerência. Ninguém pode, de antemão, provar ou refutar a filosofia ou a violência; o que se pode mostrar é o que decorre da rejeição da violência" (WEIL, 2003b, p. 21).
} 
na Introdução da Lógica da filosofia não deixam dúvidas, a filosofia é só uma possibilidade, ${ }^{6}$ mas uma vez realizada, a sua escolha engaja o filósofo, que tanto deve guardar o "segredo" de que o escopo definitivo da sua ação é essencialmente o fim da violência (WEIL, 2012, p. 35), quanto lidar com o medo de que a violência hoje refutada seja amanhã o seu destino. A decisão é sempre precária, sem garantias de sucesso, e exige a cada instante a resposta animada pela "coragem da razão".

Essa tarefa não é indiferente, e isso muito simplesmente porque "ninguém gosta do desconforto da insegurança" (WEIL, 1987, p. 19), da falta de certeza. Mais uma vez, boa parte da dinâmica da Introdução da Lógica da filosofia se desenvolve precisamente ao redor do fato de que o filósofo não vive imerso na presença do sentido nem dispõe de um mundo inteiramente sensato, mas compartilha o "mundo da vida" com o "homem comum", com o "poeta", com o "homem de ciência", com aqueles que comumente podem protestar - e efetivamente protestam - contra a filosofia, quer porque "possuem evidências e, particularmente, evidências científicas" (WEIL, 1987. p. 12), quer porque, aos seus olhos, se não impossivel, a filosofia é inútil, pois "engana os espiritos e os fecha a outras formas de saber, mais sólidas, mais salutares e mais úteis".

A rejeição do filósofo tornou-se um fato desde que Sócrates trouxe a filosofia do céu para a terra. ${ }^{7}$ Os ataques que sofreram e que sofremos, nós que escolhemos compreender, são constitutivos do ofício daqueles que Weil chama sempre de "homens de cultura" ou "homens de diálogo". Mas, paradoxalmente, esse contexto é ele mesmo uma condição da nossa esperança. Como salienta precisamente na conclusão do texto ora apresentado, a filosofia, é preciso confessá-lo, prospera durante as épocas que, com certeza, não são aquelas do silêncio, da extrema miséria, mas que não são igualmente aquelas do conforto intelectual e da tranquilidade social, política, moral: nesse sentido, não é improvável que a filosofia tenha hoje um belo futuro pela frente (WEIL, 1987, p. 21).

A derradeira consequência da escolha pela filosofia tem a ver com a compreensão de que o sentido não há de ser simplesmente apreendido no devir da história, nem mesmo contemplado nos supostos eventos prolépticos da sua presença. Antes, deve se realizar em quem o busca de forma consciente e que orienta por essa busca a sua ação, a isso chamamos moral, bem como deve se tornar presente no mundo no qual esse mesmo sentido possa ser buscado, e a essa realização chamamos política. Logo, o que está em jogo não é somente a condição para a compreensão do sentido, mas acima de tudo, pelo seu primado problemático, as condições de possibilidade para a sua realização numa vida e num mundo sensatos. Por isso, à filosofia que reflete sobre o próprio futuro, pensar a moral, a política e a educação se põe como tarefa incontornável.

À luz da candência dessa tarefa, a relevância do texto em nossas atuais circunstâncias, pensamos, não precisa ser defendida. Com efeito, e as diversas crises do nosso tempo não cessam de salientá-lo, com a pergunta acerca do futuro da filosofia está imbrincada a questão da construção das condições de possibilidade da escolha livre do filosofar. Em outros termos, trata-se sempre da questão fundamental da liberdade humana e dos problemas concernentes à realização do humano no homem, o que, em Weil, se faz também pela retomada da negatividade hegeliana, uma das chaves de ingresso na Lógica da filosofia (WEIL.

\footnotetext{
6 "A filosofia já não é a única possibilidade para o homem tão logo se tenha de admitir que ela brota de um solo que pode produzir outras plantas e outros frutos, e que os produz. O homem pode se tornar filósofo, isso é mais do que garantido, já que se pode tranquilamente concluir da existência à possibilidade; mas o mesmo princípio prova igualmente que o homem pode não se tornar filósofo. E como o filósofo o ensinou a falar razoavelmente, o homem da vida comum, aquele que não quer se tornar filósofo, é perfeitamente capaz de cuidar razoavelmente de seus assuntos, que não são os da filosofia" (WEIL, 2012, p. 27-28).

7 "Os outros o matarão? O filósofo não ignora que nada poderá contra eles, que, diante de seu tribunal tem tão poucas chances de ser absolvido quanto um médico, diante de uma corte de crianças, acusado pelo confeiteiro de ser o homem malvado que proibe aos pobres pequerruchos o que faz toda a sua alegria e os obriga a beber as poções mais amargas e repugnantes. Isso, no entanto, não o refuta; basta-lhe levar em conta o perigo: ele pode ser ridicularizado, perseguido, banido, morto, mas o que significa tudo isso diante da preocupação incessante, da pressão dos desejos e temores do homem que se entregou ao que ele chama a vida? Ou ele será morto, ou viverá como viveu até então, ser razoável em busca da presença" (WEIL, 2012, p. 31).
} 
2012, p. 17-19). Essa questão lida necessariamente com toda situação que reudza o homem, ou de uma parte dos homens, a coisa utilizável para fins que são simplesmente dados na história mundana (WEIL, 2011, p. 42). Trata-se de compreender e de enfrentar as condições do "escravo moderno", para Weil, aquele "individuo não-livre de liberdade racional e razoável, portanto incapaz de dirigir a si mesmo, realizar por si mesmo suas possibilidades de homem e aceitar suas responsabilidades" (WEIL, 2011, p. 301). Em última instância, deve-se perguntar se esse mesmo mecanismo é suficiente para dar ao indivíduo moderno não apenas a satisfação das necessidades materiais, mas, mais fundamentalmente, a chance da realização de uma vida sensata. Nunca é demais reforçar, trata-se aqui do problema da liberdade e das suas garantias. Para nós, e o autor sublinha isto insistentemente, resta, de um lado, reconhecer que o individuo pode sempre preferir "o que chamamos estado de escravo e aí encontrará satisfações de escravo sem pertubar a ordem do todo" (WEIL, 2011, p. 302). Por outro lado, pensar que esse quadro, essa é a conclusão de Weil em "O futuro da filosofia", também pelo que tem de insensato, promete um belo futuro à filosofia e ao filósofo, ou, ao menos, muita coisa para se pensar.

\section{O futuro da filosofia ${ }^{8}$}

\section{Eric Weil}

Se propus o tema do futuro da filosofia para nossas reflexões e nossas discussões (e conto muito com elas para esclarecer um tema dificil - e o meu próprio ponto de vista), é porque me parece que uma certa inquietação, para não usar termos mais dramáticos, se difundiu entre aqueles que se interessam pela filosofia e ao mesmo tempo se perguntam se não estão se ocupando com um empreendimento que só pode pretender a confiança do nosso mundo a títulos puramente históricos, o que significa sem verdadeira legitimação. A filosofia vive ainda hoje apesar dessa crise de confiança? Ela ainda tem algum sentido, alguma função, numa palavra, tem algum futuro? Ao colocar tais questões, falo da nossa situação e de um futuro que é futuro de nosso presente, e para o nosso presente; não proponho a filosofia do amanhã, não vou fazer o papel de profeta; coloco, se posso falar assim, uma questão de atualidade.

A questão exige um esclarecimento preliminar. Filosofia: em que sentido podemos dizer que ela existe ou que não existe? Existe uma filosofia ou apenas filósofos? O futuro da filosofia é o futuro dos filósofos? Em todo caso, não existe filosofia sem filósofos, como também não existe matemática sem matemáticos, nem história sem historiadores. Porém, parece haver uma tradição, uma transmissão de teses filosóficas que não passa da lembrança de uma atividade passada; mas isso nos leva de novo aos filósofos, às pessoas nas quais encontramos ou esperamos encontrar tanto uma matéria para transmitir quanto um modo de pensar e de viver que mereçam ser apresentados aos nossos ouvintes. Desse modo, tudo depende dos filósofos. Mas como caracterizálos senão pelo fato de que eles fazem filosofia, de se definirem por um tipo de ocupação que eles mesmos chamam de filosofar? Sem dúvida, não existe filosofia sem filósofos, mas da mesma forma não existem filósofos sem filosofia.

Seria conveniente, então, ver como os filósofos definem a filosofia. O projeto é natural. Mas o que vem ao espírito de forma tão natural normalmente é de valor duvidoso, e com certeza é esse o caso aqui; não surpreende que os filósofos acreditem na filosofia, eles são como todo mundo, também estão ingenuamente convencidos de que os outros escolheram mal os próprios objetivos. Ora, mas o que nos preocupa é justamente o fato de se questionar a filosofia. Então é necessário um outro passo: devemos olhar a partir da perspectiva daqueles que duvidam do sentido da ocupação dos filósofos, que não esperam nada da filosofia, dos que pensam que é preciso usar o tempo e as forças de modo mais útil, ou pelo menos de uma

8 Tradução de L'avenir de la philosophie, originalmente publicado em QUILLIEN, J. (Org.). Cahiers Eric Weil 1. Presses Universitaires de Lille: Lille, 1987, p. 9-21. Agradecemos ao professor Patrice Canivez, diretor do Insitut Eric Weil, da Université de Lille, que autorizou a publicação desta tradução 
forma mais agradável e mais promissora. Teremos assim uma possibilidade de discernir, de melhor cernir, o que é essa ocupação, cujo futuro constitui a nossa questão. Bem entendido, toda resposta, se encontrarmos alguma, será uma resposta de filósofo: nós pressupomos o interesse pela filosofia, caso contrário não a buscariamos, mas não será um puro e simples pro domo irrefletido, se chegarmos, como é previsivel, à afirmação, senão do fato de um futuro seguro para a filosofia, pelo menos àquela de um direito de viver e de uma possibilidade de renascer se esse direito não for reconhecido pelas potências intelectuais, políticas ou religiosas dos nossos dias ou dos dias das gerações que chamamos de ascendentes.

É bom admitir que a filosofia, como fato cultural, reconhece uma hostilidade tão difusa quanto proteiforme. É importante perceber este Proteu, distinguir os frontes nos quais, à primeira vista, vê-se apenas um combate confuso. Tomemos um primeiro aspecto: uma filosofia, isto é, o que um filósofo apresenta como a sua filosofia, outro pensador declara como não filosofia, como uma falsa filosofia, um erro deletério, um crime contra o espirito; ou ela caminha em direção ao abismo por caminhos que há muito tempo seguimos; ou a filosofia ainda não existe, ou não existe mais, ou a nossa época não produziu um filósofo seu; ou devemos voltar às origens, abrir novamente as fontes encobertas; ou nos afastar de toda tradição e, finalmente, pensar por nós mesmos.

Tais criticas vêm de todos os lados e são tão comuns que não precisamos ilustrá-las. As discussões que nascem nesse terreno enchem as páginas das revistas de cultura geral e alimentam as conversas dos salões, dos cafés, das redações, das reuniões de professores e de estudantes tanto do ensino regular quanto daquele superior. A situação é feita para inquietar os que gostariam de saber a que serve se dedicar à filosofia, desejo tão legitimo quanto qualquer outro e uma preocupação muito compreensivel. Mas se examinarmos o problema mais de perto, não é o futuro da filosofia que é posto em questão; ao contrário, a situação atual é julgada em nome da filosofia que vem, aquela que ainda será descoberta ou redescoberta, preparada ou estabelecida: os filósofos são julgados em nome da filosofia. A exigência de uma filosofia una, comum, universal e necessária, para retomar a célebre fórmula, não apenas subsiste, mas é proclamada com uma insistência e com uma paixão intelectual completamente voltadas para o futuro da filosofia, para a advento da verdadeira filosofia. É bem verdade que o problema da multiplicidade de filosofias sempre preocupou os filósofos, bem como em breve se mostrará central também para nossa própria pesquisa. Mas, por ora, só precisamos constatar que, neste nivel e neste contexto, a filosofia enquanto tal, isto é, enquanto ideia e ideal, não é posta em dúvida, aliás, sequer é contestada.

Mas hoje estão surgindo outras críticas que. infinitamente mais radicais, recusam e negam essa ideia e esse ideal. Desta vez, o ataque não visa a uma filosofia em nome da filosofia, não se inspira na vontade de filosofar, mas, de uma maneira sem precedentes, ele procede justamente da rejeição de toda filosofia e da vontade de filosofar. Dizem que a filosofia é impossivel, ou, supondo que seja possivel, que é inútil ou perigosa, pois engana os espiritos e os fecha a outras formas do saber, mais sólidas, mais salutares e mais úteis. No fundo, a filosofia é rejeitada porque quem a rejeita está seguro de si, enquanto o filósofo, segundo o que ele mesmo admite, ainda não possui a filosofia, o saber absoluto, ou mais exatamente, para levar em conta certos sistemas históricos e não menos importantes, ele não possui o saber que seja ao mesmo tempo absoluto e exaustivo no que concerne à totalidade do dado: este saber será aquele das estruturas lógico-ontológicas da realidade, mas não conhecimento do estruturado real. A filosofia aparece, assim, como o problema daqueles que duvidam porque não sabem, ou que pelo menos começaram pela dúvida e cujas discordâncias só podem levar à dúvida. O protesto contra a filosofia, contra o filosofar, vem então da certeza dos que têm evidências e, em particular, evidências cientificas: aos seus olhos, a filosofia não é e nunca será uma ciência, ela jamais alcançará a certeza concreta; no máximo, a filosofia constitui o terreno para as ciências nascerem. 
Encaremos o fato de que nada é mais natural do que viver na certeza; é a forma normal da vida para todos nós. Não podemos simplesmente supor que Sócrates tenha encontrado as respostas para as suas questões, que Descartes tenha descoberto o acesso às questões da vida em comunidade e da política, que Hegel tenha derrubado a pena do mestre Wilhelm Traugott Krug; devemos nos posicionar, escolher, agir aqui e agora; e fazemos isso porque estamos certos de muitas coisas. Como físicos, não paramos nossas pesquisas esperando a solução do problema do fundamento da matemática e que nos seja dada a garantia da não contradição dos axiomas fundamentais; como biólogos, não interromperemos nossos trabalhos porque ainda não dispomos de uma definição realmente precisa do ser vivo. É essa uma verdade particularmente evidente quando se trata da nossa vida cotidiana e das escolhas diante das quais ela incessantemente nos coloca. Por toda parte evidências nos guiam, sejam elas mais ou menos conscientes, expressas ou não; então, por que questionar o que nos permite viver e nos orientarmos no mundo, possuir uma ciência, possuir as ciências, nos decidir, escolher?

No entanto, esse apelo às evidências não mistura de modo completamente ilegítimo aspectos e problemas essencialmente diferentes, quer dizer, essências distintas e que devem ser distinguidas? É verdade que se trata sempre de atos humanos; mas todos os nossos atos se situam no mesmo plano? Por exemplo, o político e o físico agem no mesmo sentido da palavra "agir"? O que as nossas decisões e as nossas escolhas têm a ver com a física ou com a biologia? Com certeza podemos - e o fato prova essa possibilidade estabelecer uma ciência da natureza ou da vida; podemos igualmente constituir uma ciência da sociedade, da economia, de tudo o que se relaciona com a existência comum dos homens. Além disso, podemos compreender de que modo essas ciências influenciam as nossas decisões, as nossas escolhas e as nossas ações, como elas nos permitem desenvolver técnicas racionais, calcular as condições necessárias para o sucesso de nossos esforços, em outras palavras, as condições sem as quais o fracasso se torna inevitável. Podemos assegurar que existem relações necessárias entre os fatos; existe o que nos habituamos a chamar. com um termo ambíguo e perigoso, de leis tanto no domínio da natureza quanto naquele da história e da sociedade, das funções matemáticas ou outras ainda que descrevem os fenômenos reduzindo-os a fatores que tornam compreensivel o seu curso, compreensiveljustamente pela análise fatorial e nos limites dessa análise, repetimos, análise de fatos e de suas relações de fato. Mas se tudo isso pode intervir e intervém na decisão, a própria decisão não é tomada nem compreendida no nível dos fatos.

Não é preciso insistir sobre o caráter prático das ciências: nós nos tornamos donos e senhores da natureza, e nutrimos a esperança, uma esperança razoável, de nos tornarmos senhores da história. Mas esse triunfo presente ou esperado é o que melhor revela a ambiguidade fundamental na qual nos encontramos aqui: estamos orientados no domínio dos fatos, sem dúvida, mas não o somos no que concerne às escolhas e às ações, aquela orientação de toda a nossa existência, à qual nos referimos enquanto falávamos da ciência e das ciências. O conhecimento científico e a técnica que ele gerou nos mostram como proceder se quisermos obter um resultado qualquer; mas não nos mostram quais resultados são desejáveis. Eles nos mostram as consequências de uma decisão, mostram-nos o preço que teremos que pagar se agirmos de um determinado modo, mas ficam mudos quando thes pedimos ajuda para ir além do campo de relações hipotético-dedutivas; eles são, podemos dizer, mais do que mudos, já que o problema das preferências não é sequer formulável na sua linguagem, linguagem que ignora os termos bem e mal: na forma hipotética, qualquer coisa pode ser calculada e se tornar objeto da técnica racional, e a doença, enquanto estado fisiológico, não se distingue da saúde, outro estado, senão pelas chances de sobrevivência, quer dizer, da duração de um sistema particular, sobrevivência cuja duração maior ou menor só se torna interessante se optarmos por uma vida mais longa, uma opção que não tem nada a ver com fatos biológicos. Podemos fazer o que quisermos, 
desde que não queiramos o que for cientificamente impossivel; basta fazer o que for necessário em vista do resultado desejado, ou renunciar a esse desejo, visto o preço que a sua satisfação exigiria. Se precisamos fazer isto ou aquilo, ou se simplesmente preferimos deixar de lado a questão e fazer outra coisa completamente diferente, a ciência não nos ajudará a ver isso com clareza, embora seja certo que, sem ela, nos encontraríamos numa escuridão infinitamente mais profunda.

Ocorre então uma reviravolta completa: em vez do cientificismo, observamos hoje, sempre com mais frequência e nos meios mais diversos, um tipo de anticientificismo: a ciência e a tecnologia racionais, em vez de nos enriquecer, nos tiraram aquilo que os nossos ancestrais possuiam, aquela certeza dos valores, aquele saber mais profundo do que qualquer conhecimento calculista e que nos diz onde se encontram o bem e o mal, o que é preciso procurar e o que devemos evitar se quisermos levar uma vida sensata porque feliz, feliz porque sensata. Nós nos perguntamos em que nos podem servir todas as nossas riquezas, todo esse nosso poder atual e futuro, se ignoramos como usá-los. Nós conhecemos os fatos: eles estão aí, mudos, à nossa disposição, ao nosso serviço, esperando o que decidimos fazer com eles. Estão prontos para nos enriquecer. Mas nós já estamos sufocando nas nossas riquezas, possuímos riquezas demais, elas nos possuem, e não é a acumulação de novos "bens", um termo tão irônico nesta perspectiva, que nos tirará do nosso desespero. Pois se trata justamente de desespero, da destruição daquela esperança ingênua no progresso científico e técnico que, seguindo uma tradição que era onipotente até ontem, nós fizemos nossa.

É aqui que nasce uma nova rejeição da filosofia, uma rejeição oposta à primeira, e, se a considerarmos de perto, complementar: a filosofia não era bastante racional, nem suficientemente científica; agora, ela também é ciência, ao menos segundo as suas pretensões, e obcecada por aquele ideal de racionalidade que conhece somente relações e fatos. Ela se quer ciência das ciências; racionalidade englobante acima das racionalidades particulares e parciais e, portanto, muda quando se trata de viver; ou transmitirá um saber tradicional que, de fato, é só a ideia nobre que um grupo se dá de sua própria forma de vida, um grupo obcecado com o desejo de manter suas vantagens às custas de outros grupos; ou ela invocará a racionalidade da consciência para não ver o que se esconde sob essa racionalidade: a filosofia, em uma palavra, é apenas uma tela de proteção, uma ideologia, e seus representantes, subjetivamente convencidos da "verdade" das suas declarações, longe de corrigir o erro e a mentira objetiva da sua ideologia, apenas agravam o seu caso. A filosofia não é razão, ela é no máximo racionalização. Toda coerência é falsa coerência, a menos que um pensamento emancipado descubra uma coerência muito mais profunda do que aquela que se chama racional, lógica, científica. A filosofia se apresentava como uma justificativa, ela queria justificar as escolhas: queria, portanto, destruir a liberdade. o desejo, a revolta, a criatividade, e se mostra, assim, injustificável diante do tribunal da vida. Sem dúvida, é preciso uma fundamentação, um fundamento último; mas esse fundamento não aparecerá sobre o écran do discurso discursivo, racional, científico; também não se encontrará mais por trás desse écran uma verdade que não seja física mas metafísica. Logo, a verdade não é deduzida, mas se revela de forma imediata, ela se apresenta, quer dizer, ou ela é percebida no instante particular, ou jamais será percebida.

Entramos assim no domínio do multiforme. A aparição da vontade pura, que deseja só a si mesma, o anúncio da vida superior por vir e do homem que substituirá o ser mesquinho, anônimo, inautêntico e alienado que conhecemos, o evangelho da pureza da violência ou, ao contrário, a renúncia a tudo o que o homem comum considera desejável e a existência na indigência, ou ainda as duas coisas ao mesmo tempo, violência e renúncia purificadoras - tudo isso e qualquer outra coisa pode se tornar e de fato se torna valor e sentido absolutos aos olhos e ao coração dos crentes: o chamado, a pregação, a invocação, o oráculo, numa palavra, a linguagem livre de todas 
as restrições de uma razão tirânica, instrumental, ideológica, inconsciente do inconsciente que a põe em marcha, como dissemos, é essa nova linguagem que desvela, para nós, o que é sentido autêntico. Aceitemos a existência desses abismos que a razão queria esconder de nós, e a filosofia dos homens chamados racionais queria esquecer: cedamos à sua atração, ao mesmo tempo e indissoluvelmente, assustadora e asseguradora de uma felicidade total.

É hora de lançar um olhar para trás, para não esquecer os motivos que nos fizeram percorrer a rota que seguimos. Foi a questão do futuro da filosofia que nos guiou e examinamos os argumentos dos críticos da filosofia para melhor discernir o que é a filosofia. Talvez possamos agora estabelecer algumas conclusões.

A filosofia, podemos dizer, se apresenta, segundo aqueles que a refutam, como vontade de um discurso total, que engloba tudo e, nesse sentido. absoluto, vontade de dar, de buscar, de encontrar um sentido para os fatos parciais e particulares que as ciências e as mais variadas experiências revelam. Ela o faz relacionando toda singularidade, toda particularidade e todo dado aos objetivos humanos, aliás, ao único fim do homem que a filosofia reconhece, aquele de manter a possibilidade de um discurso verdadeiro uno, verdadeiramente coerente e realmente capaz de compreender o homem em seu mundo. Portanto, a filosofia não se contenta com as certezas ingênuas da ciência. Todavia, ela não confia nas revelações igualmente ingênuas que surgem das profundezas abissais, e está longe de acrescentar mais um mistério a tantos outros. Ela fala do que deve ser e assim confessa, aliás proclama, que o que é, quando julgado no absoluto, é incoerente e a-razoável. Mas proclama que o que é pode sempre ser levado à razão e à coerência, e reconhece o papel eminente do trabalho particular sobre o particular que as ciências realizam levando a um conhecimento autêntico, embora abstrato, abstrato embora autêntico, mas que também conduz ao sucesso sobre pensadores elevados e mistagogos quando pretende responder à questão do sentido pela referência aos fatos. A filosofia não quer negar a existência do insensato, a violência da natureza e dos homens, antes ela quer submetê-las, também não quer se precipitar na corrente das forças obscuras da alma e da história. Ela quer realizar a unidade do homem e da humanidade. se pudermos falar assim, a filosofia quer realizar a humanidade do homem num discurso feito em vista de uma ação razoável, quer dizer, universalisante, e por uma ação que se justifica num discurso que a acompanha e a fundamenta. Ela o quer, então o procura; ela não o possui e sabe, com certeza, que quer saber verdadeiramente, que quer mais do que crer que sabe.

Seus adversários viram bem: a filosofia não é uma ciência, pois the falta a ingenuidade do cientista que sabe perfeitamente que o que faz é importante, essencial, útil; a filosofia, ao contrário, sabe que toda ciência é uma abstração que esquece todos os aspectos da realidade que não aparecem em sua própria perspectiva particular; por conseguinte, sabe também que as demonstrações e os critérios de nenhuma ciência podem ajudá-la, uma vez que busca um fundamento que seja fundamento último, porque universal e total, tal que, a partir dele, o esforço das ciências possa ser examinado quanto às suas intenções inconscientes e quanto ao seu sentido para o homem, esse ser que nunca habita inteiramente no plano dos fatos e das relações entre os fatos, mas que lida sempre com fins, que deve sempre optar e que opta, mesmo quando acredita se remeter somente aos fatos, que nunca é físico, sociólogo ou médico, mas que faz matemática, fisiologia ou direito, - que as faz, mas que poderia fazer outra coisa e que faz sempre outra coisa: não nos apaixonamos enquanto cientistas. A filosofia não é ciência; mas se é a busca da coerência exaustiva que constitui a ciência, então ela é mais científica do que tudo o que carrega esse nome no uso comum.

Pela mesma razão, ela também não é a revelação de um segredo último, uma profecia ou o anúncio de uma salvação absoluta: ao contrário, ela põe em questão todos os valores, tudo o que é caro aos homens ou porque foi caro aos seus ancestrais ou porque os seduz pela novidade do que é inédito: a 
filosofia examina tanto a tradição quanto a revolução, os pensamentos dos bem-intencionados e aqueles dos que derrubam e quebram as mesas do seu tempo. A filosofia reconhece toda certeza moral, estética e social - ela as arrasta para o seu tribunal, ou melhor, faz todas elas entrarem na dança que as reúne ao opô-las -, porque todas são atos dos homens que as vivem e porque nenhuma delas goza, aos olhos da filosofia, de um direito preeminente que dispense da obrigação de exibir as próprias credenciais, as próprias garantias. Os valores existem no mundo tanto quanto a ciência: a questão não é fazer távola rasa de toda regra tradicional, de todo conhecimento e de todas as técnicas particulares. Mas, embora reconhecendo que devemos continuar a procurar e a trabalhar, como todo mundo, a viver juntos se não optarmos pela morte, a filosofia vê nas regras, nas ciências, em tudo o que chamamos evidente, natural e incontestável, fatos humanos que devem ser relacionados ao ideal de uma coerência absoluta, à ideia de um mundo humano uno, organizado e, portanto, sensato.

Eis o que a filosofia procura, eis o que constitui a filosofia: a busca daquele que quer compreender, porque compreende que ainda não compreendeu e que se debate num mundo incompleto, num quase-mundo incoerente, mas que contém coerência suficiente para que o desejo de uma coerência verdadeira e total possa nele surgir e de fato surja, historicamente. A filosofia, podemos dizer, está nos antípodas da ingenuidade, ela procede da dúvida mais radical, infinitamente mais radical que a dúvida cartesiana, colocando em questão até mesmo o ideal de uma ciência da realidade empírica que inspira a dúvida metódica. A filosofia não crê nada, não crê em nada, sabe que não sabe nada, só existe uma coisa da qual ela está certa, a saber, de sua própria vontade de compreender, de unificar os discursos dos homens em um discurso que reduza toda peculiaridade, toda parcialidade ao seu papel de elemento de um Todo que não seria Todo sem esse elemento, por mais arbitrário ou por mais violento que ele seja em sua recusa da compreensão, mas que, apesar disso, é apenas um elemento do Todo.
Por consequência, a filosofia é essencialmente desconfortável; e o é também para os que se dedicam a ela, e talvez ainda mais para os que se veem envolvidos nessa dança das peculiaridades da qual falamos. Ora, ninguém gosta do desconforto da insegurança e da busca incessante de unidade e de sentido: é muito mais agradável estar seguro, conhecer a boa estrada, saber a verdade verdadeira, em vez de ter que tatear numa realidade obscura, ambigua, vaga e cambiante. Ninguém se torna filósofo enquanto puder evitar a filosofia, enquanto as evidências de sua herança ou aquelas da própria recusa a essa herança fornecerem o que serve de orientação e de mundo. Além disso, podemos sempre recusar a questão do sentido e nos estabelecer na insensatez aceitada e proclamada, na violência pura e conscientemente insensata: podemos optar contra a filosofia, contra toda forma de razão. Decorre daí - e isto é decisivo - que o próprio filósofo não fez mais do que optar, numa opção livre, em favor da razão e, portanto, sem uma razão prévia: a razão e as razões só podem nascer de uma opção deste tipo. Se há uma diferença entre a vontade de violência e aquela de filosofar, ela consiste apenas no fato de que o filósofo pode compreender o violento, enquanto o violento não compreende o filósofo, já que ele recusou a compreensão.

Então, qual será o futuro da filosofia e dos filósofos? Provavelmente a resposta não será a mesma para as duas questões. É possivel, de fato - e essa possibilidade se tornou realidade mais de uma vez, tanto no passado como em nosso presente -, que a violência se imponha ou que uma revelação, religiosa, antirreligiosa, para-religiosa, convença uma maioria ou um grupo dirigente ou que a maioria ou que os dirigentes defendam uma tradição sagrada que não suporta se ver questionada. Portanto, pode acontecer que os filósofos, esses céticos, esses descrentes, esses encrenqueiros, sejam reduzidos ao silêncio, pela censura ou nas prisões, ou, o que é sempre o mais seguro, pelo carrasco. Estariamos totalmente equivocados se nos esquecêssemos dessa possibilidade: 
Sócrates não foi o único a passar pelo tratamento radical reservado aos estraga-prazeres.

A filosofia seria então reduzida ao silêncio, já que a filosofia não é nada mais do que o que ocupa e preocupa os filósofos. Entretanto, podemos nos perguntar se, emudecida, a filosofia ao menos não subsistiria nos escritos e no pensamento tácito ou astuciosamente camuflado de alguns homens: uma indicação, para não dizer uma prova, está no fato de que ela sempre ressuscitou e se fez de novo ouvir tão logo fossem diminuidas a pressão moral, intelectual e policial, a censura, institucionalizada ou não. A busca pelo discurso filosófico renasce, são estabelecidos de novo os laços com o pensamento, com os pensamentos anteriores ao tempo do silêncio forçado, e a questão do sentido é re-colocada. Em tais circunstâncias, essa questão pode ser posta de modo equivocado, usando uma linguagem superada pela evolução da realidade, talvez ela se apresente simplesmente como parte de uma suposta cultura geral, como saber histórico, saber do passado e saber passado porque só do passado. Ainda assim, ela despertará as questões reprimidas, fará ver que os problemas, e os problemas radicais, existiram para homens aos quais seria difícil não respeitar, e que tais problemas podem muito bem ser encontrados por trás das dificuldades e dos desgostos do presente: o que se ressente como uma vaga inquietação poderia, com a ajuda de tais confrontos, ser cernido, analisado, erguido à luz da razão, pelo retorno da ideia - e à ideia - de coerência total.

Mas essa passagem para a filosofia nasce e renasce sempre de uma decisão livre. Decisão pela busca e pelo questionamento: para começar. tudo o que nós sabemos é que não sabemos, mesmo sabendo muitas coisas, a menos que definamos arbitrariamente como saber último um conhecimento das estruturas sem conhecimento do estruturado, conhecimento do discurso, não do que ele diz. Sempre teremos que nos colocar de novo diante da questão do sentido num mundo sensato-insensato. É claro também que podemos escapar disso, e escapamos de fato quer pelo cientificismo, quer pelo profetismo. É imaginável, até mesmo observável, que uma comunidade inteira esteja tão convencida da verdade de sua tradição que a dúvida e a inquietação não encontrem espaço nela. Mas não parece que as tradições existentes no nosso mundo moderno possam inspirar uma fé desse tipo: todas as tentativas de impor novas crenças evidentes e. como dizem tão bem, sem se dizer, só levaram a uma luta de deuses pesando sobre as costas dos homens. Um mundo de certeza, mas de uma certeza universal, de todos e de cada um, é um ideal, e é também o critério indispensável de todo ideal particular e parcial; mas o mundo, o nosso mundo, não é uno, bem como não o é o nosso discurso, e ainda não transcorreu o tempo necessário ao trabalho para a unificação do mundo e do pensamento.

A filosofia terá seu lugar nesse mundo, pelo menos terá direito a um lugar nele enquanto a palavra "direito" significar alguma coisa. Mas nada lhe garante que o mundo no qual este lugar se encontra seja especialmente confortável: ao contrário, a voz da filosofia será ainda mais clara e melhor entendida num mundo do desconforto, da insegurança e da falta de evidências indubitáveis, em outros termos, mundo no qual as certezas particulares e parciais se enfrentarão com violência ou confessarão a própria incapacidade de responder às questões que os homens colocarão e se colocarão enquanto homens e não nos seus diferentes papéis de especialistas. A filosofia, é preciso admitir, prospera durante as épocas que, com certeza, não são aquelas do silêncio, da extrema miséria, mas que também não são as do conforto intelectual e da tranquilidade social, política e moral: neste sentido, não é improvável que a filosofia tenha hoje um belo futuro pela frente. Infelizmente, responderá o homem carnal em nós.

\section{Referências}

BERNARDO, L. M. Reasons of violence. Violence of reason: an interpretation based on Eric Weil's core paradox. In: AURÉLIO, D. P. and PROENÇA, J. (Org.). Terrorism: Politics, Religion, Literature. Cambridge: Cambridge Scholars Publishing, 2011. 
CASTELO BRANCO, J.; COSTESKI, E. Observações sobre o hegelianismo de Eric Weil. In: WEIL, E. Hegel e nós. Caxias do Sul: EDUCS, 2019, p. 17-34.

CHIARA, L. 50 Ans: Université Nice Sophia Antipolis. Hisotire d'une université d'aujourd'hui, 2015. Nice: Université Nice Sophia Antipolis, 2015. Disponivel em: https://issuu.com/comuns/docs/uns_livre_5oans_web2. Acesso: 18 out. 019.

HADOT, P. A filosofia como maneira de viver. Tradução de M. C. Malimpensa. São Paulo : É Realizações, 2016.

LYOTARD, J.-F. Por que filosofar? Tradução de M. Marcionillo. São Paulo : Parábola, 2013.

SICHIROLLO, L. La dialettica degli antichi e dei moderni. Studi su Eric Weil. Bologna: Il mulino, 1997.

WEIL, E. Hegel e nós. Caxias do Sul: EDUCS, 2019.

WEIL, E. Lógica da filosofia. Tradução de Lara C. Malimpensa. São Paulo : É Realizações, 2012.

WEIL, E. Filosofia política. Tradução de Marcelo Perine. São Paulo: Loyola, 2011.

WEIL, E. Philosophie et réalité I. Paris: Vrin, 2003a.

WEIL, E. Philosophie et réalité II. Paris: Vrin, 2003b.

WEIL, E. L'avenir de la philosophie. In: QUILLIEN, J. (org.). Cahiers Eric Weil 1. Lille: Presses Universitaires de Lille, 1987. p. 9-21.

WEIL, E. Violência e linguagem. In: CENTRO CATÓLICO DE INTELECTUAIS FRANCESES. A violência. Tradução de Anna Maria Gonçalves. Rio de Janeiro: Laudes, 1969.

\section{Endereço para correspondência}

Judikael Castelo Branco

Universidade Federal do Tocantins (UFT) | Câmpus de Palmas

Avenida NS 15, Quadra 109 Norte | Plano Diretor Norte

Bloco Bala II, Sala 20

77001-090

Palmas, TO, Brasil 